\title{
RESPOSTA EMOCIONAL À PUBLICIDADE EM MÍDIAS SOCIAIS
}

EMOTIONAL RESPONSE TO ADVERTISING IN SOCIAL MEDIA

Recebido em 09.07.2015. Aprovado em 30.03.2016

Avaliado pelo sistema double blind review

DOI: http://dx.doi.org/10.12712/rpca.v10i1.628

\section{Ivanete Schneider Hahn}

ivischneider@hotmail.com

Universidade Federal de Santa Maria (UFSM), Santa Maria/RS, BRASIL

\section{Flavia Luciane Scherer}

flaviascherer@globo.com

Universidade Federal de Santa Maria (UFSM), Santa Maria/RS, BRASIL

\section{Maria Carolina Serpa Fagundes de Oliveira \\ mc.sfagundes@gmail.com \\ Universidade Federal de Santa Maria (UFSM), Santa Maria/RS, BRASIL}

\section{Régis Scheid}

reegis.scheid@gmail.com

Faculdade de Itapiranga (FAI), Itapiranga/SC, BRASIL

\section{Resumo}

Este estudo partiu da lacuna teórica de que as investigações sobre a publicidade em mídias sociais não costumam descrever as emoções dos consumidores sobre os anúncios. Deste modo, se propôs a descrever as respostas dos consumidores para anúncios reais expostos em duas comunidades de marca no Facebook: uma de marca icônica e a outra de uma marca local. Foram conduzidos dois levantamentos de campo, sendo que o primeiro ocorreu com 985 seguidores da marca icônica e o segundo com 233 consumidores da marca local. Os resultados permitem concluir que (1) o tipo de anúncio parece não influenciar diretamente o desejo de compra/ consumo do produto; (2) a crença dos seguidores a respeito da marca afeta a reação emocional aos anúncios; (3) as características sociodemográficas (escolaridade e gênero) não se mostraram significantes na análise dos anúncios.

Palavras-chave: Marketing. Publicidade. Comunicação.

\section{Abstract}

This study started from the theoretical gap that investigations on advertising in social media usually does not describe the emotions of consumers about the ads. Thus, it was proposed to describe consumer responses to real advertisements exposed in two Facebook communities: an iconic brand and a local brand. Two surveys were conducted. The first was directed to 985 followers of the iconic brand and the second to 233 consumers of a local brand. The results show that (1) the kind of ads does not directly influence the purchase intention or consumption of the product; (2) the belief of followers about the brand affects the emotional response to the ads; (3) sociodemographic characteristics (educational level and gender) were not significant in the analysis of the ads.

Keywords: Marketing. Advertising. Communication. 


\section{Introdução}

As atividades em mídias sociais representam uma fração substancial do tempo gasto na internet (GOEL et al., 2012). Nestas ferramentas de comunicação, os usuários costumam criar representações explícitas de suas relações com outros usuários (seus pares) (BOYD; ELLISON, 2007), e estabelecem conexões com outras entidades, a fim de expressar suas identidades e de se inscrever para receber seu conteúdo (SUN et al., 2010).

A ampla adoção dessas tecnologias tem levado as empresas a investir mais esforços em comunicação com os consumidores por meio das mídias sociais (CHI, 2011), o que de acordo com Lin (2006), permite maior proximidade e interação das empresas com os consumidores. Neste cenário, os gerentes de marca comumente investem em dois tipos de comunicação de marketing: publicidade digital interativa ou as comunidades virtuais de marca. A primeira refere-se às mensagens relacionadas à marca que são diretas ao consumidor (KELLER, 2009), enquanto a segunda almeja incentivá-los a se envolver e engajar com as ações da marca (CASALÓ et al., 2008; TUCKER, 2012).

A abordagem de comunicação mais comum enfoca os recursos das mídias sociais, de tal forma que as conexões sociais se transformam em canais de comunicação da marca (RUSSELL, 2009). Assim, as mídias sociais mostram-se adequadas para ações de publicidade e marketing viral (GOLAN; ZAIDNER, 2008; UTZ, 2009) e de marketing boca-a-boca (LIBAI et al., 2010). Tal tendência de marketing levanta preocupações sobre como otimizar os efeitos da comunicação de marketing no contexto das mídias sociais. Do ponto de vista prático, uma questão fundamental refere-se às respostas ao marketing em mídias sociais. Nesse sentido, estudos recentes mostram que a experiência com mídias sociais influencia as respostas do usuário para compras online e publicidade (CHA, 2009; HOY; MILNE, 2009; KELLY et al., 2010). Influenciam ainda o comportamento do consumidor a respeito da consciência, a aquisição de informações, opiniões, atitudes, comportamento de compra e pós-compra, comunicação e avaliação (MANGOLD; FAULDS, 2009).

Apesar do marketing em mídias sociais ser um tema amplamente pesquisado, ao rever a literatura, verificouse que estudos tem-se concentrado em descrever o que é o marketing em mídias sociais (pesquisas teóricas), bem como em examinar quais fatores afetam o comportamento do consumidor em relação à rede social (basicamente experimentais). Apesar dos primeiros progressos realizados por pesquisadores, o desenvolvimento nesta área de estudo tem sido limitado, uma vez que os estudos não costumam descrever os benefícios que as empresas auferem com essa tática de marketing, o quanto os consumidores lembram dos anúncios, ou ainda suas emoções sobre os anúncios.

Identificadas estas lacunas, este estudo descreve as respostas dos consumidores para anúncios reais expostos em comunidades de marca. A análise objetiva compara anúncios de uma marca icônica e de uma marca local, observando que o amplo investimento em mídias sociais parece mais frequente em marcas icônicas e pouco se conhece as marcas locais. O Facebook, maior site de redes sociais existente atualmente e que tem atraído milhões de usuários em todo o mundo (TUBENCHLAK et al., 2015), muito popular no Brasil, convém como cenário de estudo, e nele foram identificadas duas marcas (a icônica Coca-Cola e uma local: empresa fotográfica) para servir de base à pesquisa. Além disso, é importante ressaltar que as publicidades contêm elementos emocionais, que merecem ser elucidados.

Deste modo, o artigo estrutura-se em cinco seções, sendo esta primeira destinada ao embasamento e justificativa da proposta de estudo. A segunda seção apresenta a fundamentação teórica, que expõe pesquisas teóricas e empíricas, destacando os conceitos mais relevantes sobre o marketing e publicidade em mídias sociais. A terceira seção apresenta a metodologia que fundamenta as pesquisas empíricas, seguida da apresentação dos resultados e sua discussão. Finalmente, mostram-se as principais conclusões do estudo, suas limitações e parâmetros futuros de pesquisa.

\section{0 marketing e a publicidade em mídias sociais}

As redes sociais online tornaram-se uma avenida pela qual as empresas podem estender suas campanhas de marketing para uma ampla gama de consumidores. Chi (2011, p.46) define marketing de mídia social como uma "conexão entre marcas e consumidores, oferecendo um canal pessoal centrado no usuário de rede e na interação social". As ferramentas e abordagens para a comunicação com os clientes mudaram muito com o surgimento dos meios de comunicação online, forçando as empresas a aprender a usar as mídias sociais de uma forma que é consistente com o seu plano de negócios (MANGOLD; FAULDS, 2009).

A publicidade online foi introduzida em 1994 na forma de anúncios (ROBINSON et al., 2007). Ao longo dos anos, o marketing online continuou crescendo, devido ao potencial de alcance global, interatividade e, por ser mais eficaz na capacidade de segmentação (DREZE; HUSSHERR, 2003; YAVEROGLU; DONTHU, 2008). No entanto, a eficácia da publicidade na 
internet tem sido o assunto de interesse substancial da academia e de gerentes de marketing. Apesar de um começo promissor, o uso da internet como meio de publicidade tem sido questionado devido ao fato de os consumidores parecerem evitar anúncios online (PINHO; SOARES, 2015). Não obstante, dada a sua natureza, a publicidade online é percebida como menos confiável do que outras formas de comunicação. A partir dessa premissa, muitos estudos buscaram verificar por que os anúncios parecem ineficazes (DREZZE; HUSSHER, 2003; KELLY et al., 2010). Os autores verificaram que os anúncios online impactam de modo tradicional a memória. Assim, sugerem que as mensurações de anúncios online podem seguir os padrões tradicionais de mensuração de anúncios (DRĖZE; HUSSHER, 2003).

Outros esforços, contudo, mostram que a publicidade online pode ser efetiva para a empresa, podendo ser eficaz nas respostas dos usuários para compras online (CHA, 2009; HOY; KELLY et al., 2010; MILNE, 2009), a respeito da consciência, a aquisição de informações, opiniões, atitudes, comportamento de compra e póscompra, comunicação e avaliação (MANGOLD; FAULDS, 2009) e principalmente no que tange à lealdade à marca (ERDOGMUS; ÇIÇEK, 2012).

Assumindo que estas mídias podem ser eficazes para as empresas, cabe destacar uma diferença fundamental entre a publicidade tradicional e a online, que é o grau em que o consumidor tem o controle sobre a exposição de publicidade (SCHLOSSER et al., 1999). Neste ambiente, as empresas devem mudar a filosofia do "tentar vender" para "construir relacionamentos", por meio de pequenas ações (COON, 2010). Esta abordagem favorece a quantificação das reações dos consumidores para publicidade em mídias online por meio do número de cliques e hits e medidas de eye-tracking (DRĖZE; HUSSHER, 2003). Contudo, essas mensurações não necessariamente mostram os sentimentos dos consumidores em relação à publicidade (de modo direto), mas apenas evidenciam a interação que ocorreu entre o consumidor e o anúncio.

\section{Fatores que influenciam a avaliação da publicidade em mídias sociais}

Por muitos anos, grande parte da literatura em publicidade aderiu à noção de que as respostas aos anúncios publicitários caem em um único fluxo causal de efeitos, ou seja, não importa o quão complicado ou simples, todos os modelos consideravam a hipótese central de que, para ser eficaz, a publicidade deve levar as pessoas por uma série de etapas de processamento (THORSON et al. 1992). No decorrer do tempo, como mais importantes no esquema hierárquico, revelaram-se os atributos do anúncio em si e como cada um desses atributos antecipa as várias respostas ao anúncio: atenção, memória, atitude e conação (ZIKHAN; BURTON, 1989). Provavelmente, o elo mais estudado até então, foi o que compreende os atributos de anúncios e respostas atitudinais, enquanto outros estudos voltaram sua atenção para os atributos emocionais de anúncios e respostas comportamentais.

Na última década, a efetividade da publicidade tornouse um dos mais importantes temas de pesquisa em marketing (GHOSH; BHATNAGAR, 2013), uma vez que os anunciantes investem seus esforços em implementar programas que maximizem o retorno do investimento em mídias. A maior parte das pesquisas sobre a eficácia da publicidade é derivada da publicidade tradicional e tem se concentrado no número de pessoas expostas ao anúncio (alcance e frequência). Esta medida tem sido criticada, pois embora o aumento do alcance e/ou a frequência pode aumentar a eficácia de uma campanha, ela pode rapidamente tornar-se muito cara (FARRIS et al., 2006), bem como é possível que um consumidor tenha sido exposto a um anúncio, mas não ter dado nenhuma atenção a ele (LEE; AHN, 2012). Nesse sentido, alguns estudos identificaram o papel da mensagem publicitária para mudar a percepção dos consumidores sobre o produto anunciado (CHANG, 2002; SHAO, 2002).

Não obstante, na atualidade a literatura aponta uma série de fatores capazes de influenciar a eficácia de um anúncio online, como as características do consumidor, tais como gênero e cultura (PALANISAMY, 2005; JU, 2013); os elementos da campanha (YAVEROGLU; DONTHU, 2008); e as características do anúncio (BARAGGIOLI; BRASEL, 2008). Outros pesquisadores têm estudado o papel do tamanho do anúncio (BALTAS, 2003), a colocação deste (ROSENKRANS, 2010) e a duração da exposição (WANG et al., 2013) sobre a eficácia do anúncio.

Infere-se ainda, que a mensagem de marketing depende dos benefícios que os consumidores-alvo procuram. Os gestores de marketing devem primeiro determinar em que sua mensagem publicitária se concentra e quais questões são relevantes para seus clientes-alvo (GHOSH; BHATNAGAR, 2013) e então, avaliar seus anúncios. 


\section{A resposta emocional}

As emoções são estados afetivos caracterizados por episódios de intensos sentimentos associados a algum fator em específico e instigam comportamentos reacionais específicos (COHEN; ARENI, 1991). Vários estudos investigaram o papel da emoção no comportamento do consumidor. As primeiras pesquisas se concentraram principalmente em respostas emocionais dos consumidores à publicidade (por exemplo, EDELL; BURKE, 1987).

Outros estudos examinam as emoções geradas pelo uso do produto (HOLBROOK et al., 1984), serviços (OLIVER, 1994) ou situações de consumo (DERBAIX; PHAM, 1991). Pesquisadores também investigaram o impacto da emoção de consumo sobre a satisfação (LADHARI, 2007) e as intenções comportamentais (ZEELENBERG; PIETERS, 2004). Outro estudo, sugere que a resposta emocional corresponde sistematicamente a diferentes percepções de satisfação, confiança e compromisso (SCHOEFER; DIAMANTOPOULOS, 2009).

Cabe ressaltar que as empresas costumam utilizar apelos emocionais em seus anúncios como forma de criar laços afetivos dos consumidores com a empresa. Neste sentido, do ponto de vista prático, uma questão fundamental refere-se às respostas ao marketing em mídias sociais. Reconhecendo que a experiência com mídias sociais influencia as respostas dos usuários para compras on-line e publicidade (CHA, 2009; HOY; MILNE, 2009; KELLY et al., 2010) e a aquisição de consciência, de informações, opiniões, atitudes, comportamento de compra e póscompra, comunicação e avaliação (MANGOLD; FAULDS, 2009), torna-se cogente explorar a reação dos consumidores aos anúncios nestas mídias. Neste sentido, a próxima seção apresenta os procedimentos metodológicos do estudo a campo.

\section{Procedimentos Metodológicos}

Este estudo caracteriza-se por sua abordagem quantitativa e descritiva, operacionalizado por meio de duas surveys. Como cenário de estudo, face às diversas mídias sociais, optou-se por utilizar como meio de análise o Facebook. O Facebook é um site e serviço de rede social lançado em fevereiro de 2004 para promover a interação entre as pessoas e possui mais de um bilhão de usuários ao redor do mundo
(SOCIALBAKERS, 2012). No Brasil, o Facebook é o líder entre os sites de redes sociais com mais de 76 milhões de usuários em julho de 2013 (REUTERS BRASIL, 2013) representado aproximadamente 38\% de penetração na população brasileira.

\section{0 instrumento de coleta de dados}

Uma das escalas de mensuração da reação à publicidade, amplamente explorada na literatura é a reação emocional à publicidade, proposta por Wells (1964). O autor desenvolveu uma escala para mensurar o apelo emocional em publicidades impressas. Não obstante, os pesquisadores tiveram interesse em criar uma escala que pudesse traçar os perfis multifuncionais, com o objetivo de captar, sob a perspectiva do consumidor, a reação emocional imediata aos anúncios impressos (ZIKHAN; BURTON, 1989).

Mesmo que esta escala tenha sido desenvolvida para mensuração de anúncios impressos, ela vem sendo amplamente utilizada para mensurar a reação à publicidade em outras mídias, como a televisão e mais recentemente no ambiente online (MELLO et al., 2006), não tendo alterado, ao longo do tempo, sua formulação original - que vem sendo considerada consistente.

Neste estudo, especificamente, a escala utilizada é também conhecida como quociente emocional de Wells. Esta escala é composta por 12 variáveis observáveis e é pontuada da seguinte forma: o número de acordos, sendo seis itens (favoráveis) mais o número de discordâncias, também com seis itens (desfavoráveis) é dividido por 12 e multiplicado por 100 para produzir um número entre 0 e 100 (a multiplicação por 100 é simplesmente remover o decimal.) para obter uma pontuação única para um anúncio publicitário, procede-se uma média das pontuações recebidas de todos os entrevistados (WELLS, 1964).

Deste modo, para a coleta dos dados, em ambos os estudos, os anúncios foram apresentados e em seguida aplicou-se o instrumento, que dividiu-se em duas partes. $\mathrm{Na}$ primeira parte, os participantes recebiam as 12 afirmações que compõem o quociente emocional. Analisando a literatura verificou-se que Mello et al. (2006) traduziram e utilizaram a escala para analisar anúncios feitos no contexto online. Deste modo, utilizou-se a versão traduzida, dispensando, desse modo, os procedimentos de tradução e préteste.Utilizou-se uma escala Likert, pela qual os 
respondentes atribuíram graus de concordância entre 1 (discordo totalmente) e 5 (concordo totalmente) para a mensuração das variáveis. A segunda parte do instrumento de coleta de dados, continha questões relativas ao perfil dos respondentes, como: gênero, idade, estado civil e formação.

\section{Operacionalização da análise com seguidores de uma marca icônica}

A Coca-Cola é uma marca icônica, presente em mais de 200 países e responde por mais de 400 marcas de bebidas não alcoólicas, entre estas, quatro das cinco marcas mais consumidas no planeta: Coca-Cola, CocaCola light, Fanta e Sprite. Além disso, a marca foi reconhecida por 13 anos consecutivos como a marca mais valiosa do mundo (INTERBRAND, 2012). A Coca-Cola é ainda a marca mais seguida no Facebook com mais de 73 milhões de seguidores ao redor do mundo (SOCIALBAKERS, 2013). A empresa é conhecida por seu forte investimento em advertising, bem como é reconhecida por aplicar programas para engajar os consumidores online, oferecendo promoções, downloads gratuitos, CDs entre outros (MANGOLD; FAULDS, 2009). A escolha do post (publicidade) de análise deu-se por este integrar uma grande ação de marketing da Coca-Cola. O anúncio alcançou na fan page mais de 3.700 curtidas, mais de 2.400 compartilhamentos e centenas de comentários.

Para a operacionalização da pesquisa, o universo do estudo foi composto por todos os brasileiros, usuários de mídias sociais, inscritos no Facebook, sendo aproximadamente 76 milhões de usuários (REUTERS BRASIL, 2013). Enviou-se um convite, por meio das redes de contato dos pesquisadores, pelas mídias digitais (e-mail, Facebook, grupos fechados...) contendo um link online para preenchimento da pesquisa. A coleta ocorreu dentro da perspectiva do snowball sampling, método que não se utiliza de um sistema de referências, mas sim de uma rede de amizades dos membros existentes na amostra (GOODMANN, 1961).

Obteve-se 1.037 questionários, com respondentes de 20 estados brasileiros, que constituíram a amostra inicial da pesquisa. Os questionários passaram inicialmente por análises de preparação da matriz de entrada de dados. Procedeu-se assim a identificação de missing values, por uma distribuição de frequência simples dos dados faltantes, não havendo valores ausentes. Em seguida, verificou-se os valores atípicos por meio do cálculo da Distância de Mahalanobis (nível de sig. 0,001), sendo identificados 52 outliers, que foram excluídos. Deste modo, a amostra correspondeu a 985 questionários válidos. Esta amostra, contudo, não pode ser considerada como probabilística, haja vista que a probabilidade de inclusão de cada membro da população na amostra não é conhecida e nem equivalente (MALHOTRA, 2001).

Finalmente, verificou-se a normalidade dos dados, por meio do teste de Kolmogorov-Smirnov, com correção de Lilliefors, que indicou que os dados têm distribuição normal.

\section{Operacionalização da análise com seguidores de uma marca local}

A segunda etapa do estudo foi conduzida com consumidores da uma marca local, que é uma empresa fotográfica, que atua há mais de 20 anos no mercado de uma cidade do interior de Santa Catarina e que vem investindo em ações de marketing em mídias sociais, considerando o tipo de serviço prestado e o novo público consumidor. Por solicitação da empresa, a marca não será divulgada no estudo.

A escolha do post (considerado como publicidade) de análise deu-se por este integrar uma ação de marketing da empresa e por seu alcance na fan page da organização, sendo que a imagem alcançou 1.590 visualizações e mais de 100 curtidas em três dias.

A empresa atende demandas em basicamente três cidades, totalizando um público-alvo total de aproximadamente 20.000 pessoas, sendo este o universo deste estudo. Para participar da pesquisa, o requisito consistia no respondente ser usuários de mídias sociais e inscrito no Facebook. A coleta de dados ocorreu por meio de questionário online.

A amostra inicial da pesquisa correspondeu a 241 questionários. Os questionários passaram pelas análises para identificação de missing values, não havendo valores ausentes. Em seguida, verificou-se os valores atípicos por meio do cálculo da Distância de Mahalanobis (nível de sig. 0,001), sendo identificados oito outliers, que foram excluídos. Deste modo, a amostra final corresponde a 233 questionários válidos, que também não representa uma amostra estatística. A análise da normalidade dos dados indicou que os dados têm distribuição normal.

\section{Caracterização das amostras}

De modo a localizar a amostra na população do estudo, esta seção detalha o perfil dos respondentes 
de ambos os estudos. A Tabela 1 permite verificar uma grande amplitude etária de ambas as amostras, embora a média de idade seja relativamente jovem.

Tabela 1: Perfil das duas amostras

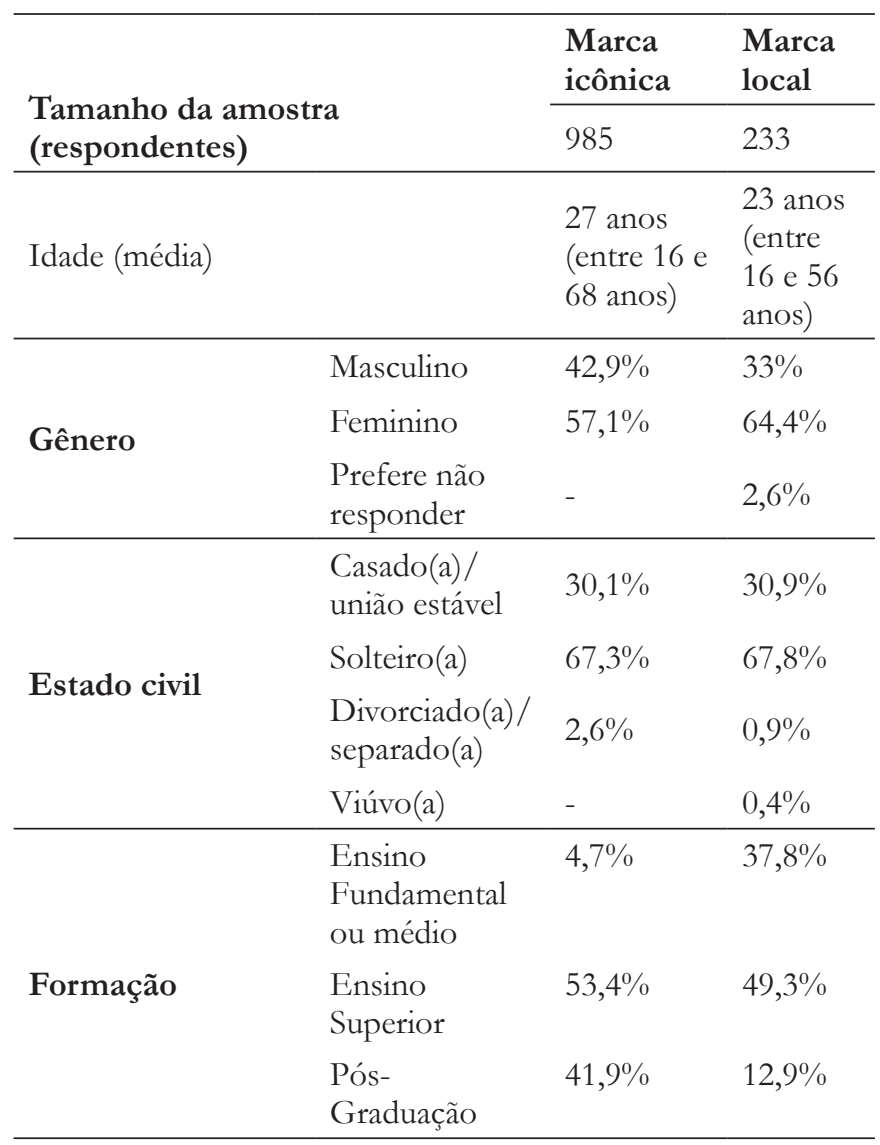

Fonte: elaborado pelos autores (2015)

As mulheres respondem pela maioria dos respondentes em ambas as amostras, assim como grande parte dos respondentes é solteiro. Verifica-se ainda que a amostra da marca icônica possui elevado nível de escolaridade, em comparação à marca local, o que pode evidenciar as características demográficas da região de cobertura da empresa de fotografias.

\section{Resultados}

De modo a descrever as respostas dos consumidores para anúncios reais expostos em comunidades virtuais de uma marca icônica e de uma marca local, esta seção apresenta os resultados dos levantamentos de campo. Inicialmente, apresentam-se as duas inserções, conforme pode ser observado nas Figuras 1 e 2.

Ambas as imagens acompanhavam um texto publicitário com o objetivo de instigar o consumo dos produtos/serviços das respectivas marcas. Os dois anúncios são em forma de post em fan page, um tipo de publicidade que costuma ser utilizado para aumentar a notoriedade da marca junto aos diversos públicos da empresa, ou seja, desde os clientes potenciais, até os usuários que já seguem a página da empresa. Contudo, as imagens possuem tipos diferentes de mensagem.

A Imagem 1, que refere-se à inserção da marca local, foca sua mensagem em mostrar o próprio serviço da empresa, isto é, a fotografia endossada é fruto de um trabalho que foi feito pela empresa. O texto que acompanha a imagem volta-se a identificar os sujeitos e instigar o consumo de seus serviços.

A Imagem 2, que é a inserção em forma de post da marca icônica, tem como prioridade aparente comunicar-se com clientes e potenciais clientes e mantê-los envolvidos em sua ação. Esta análise está pautada no tipo de texto que acompanhava o anúncio, que referia-se à uma questão que forçava os seguidores a emitir sua opinião e engajar terceiros com a página. Não obstante, a imagem fez parte de uma campanha de marketing que também abrangeu outras mídias.

\section{Imagem 1: Imagem de análise da marca local}

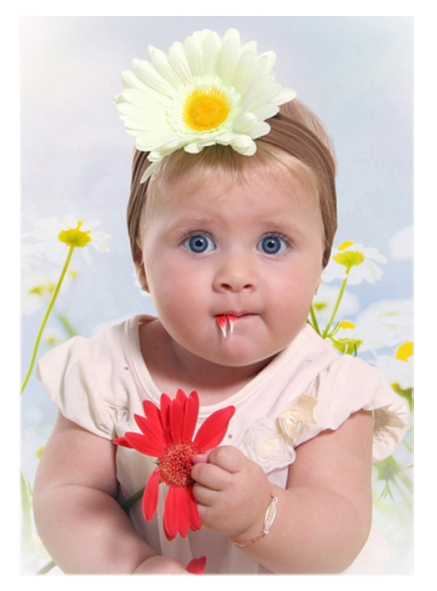

Imagem 2: Imagem de análise da marca icônica

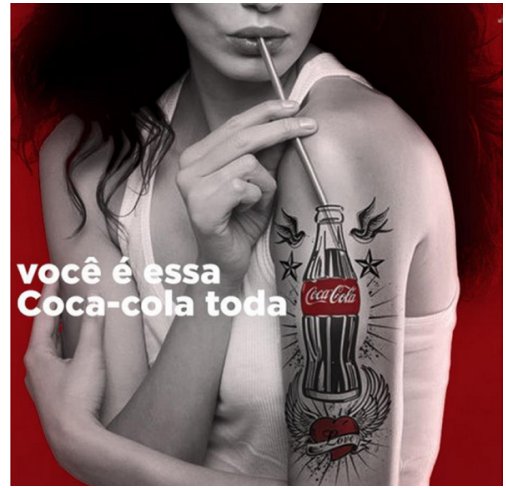


Infere-se que ambas as imagens foram escolhidas, considerando o engajamento preliminar que as imagens obtiveram em seus posts originais na linha do tempo de ambas as marcas. Assim, considerou-se que estas inserções estavam aptas a estimular reações emocionais nos consumidores, requisito para análise à qual este estudo se propôs.

Tendo por base estas imagens, os respondentes de ambos os levantamentos foram convidados a responder a escala do quociente emocional de Wells. Deste modo, a Tabela 2 apresenta os resultados do desempenho das marcas em cada item que compõe a escala. Conforme proposta original da escala, algumas variáveis observáveis apresentam-se escritas de maneira desfavorável (e assim são utilizadas no cálculo do quociente emocional).

\section{Tabela 2: Análise da reação emocional à publicidade por amostra}

\begin{tabular}{|c|c|c|c|c|}
\hline \multirow[b]{2}{*}{ Variáveis } & \multicolumn{2}{|c|}{ Marca Icônica } & \multicolumn{2}{|c|}{ Marca Local } \\
\hline & Média & $\begin{array}{l}\text { Desvio } \\
\text { Padrão }\end{array}$ & Média & $\begin{array}{l}\text { Desvio } \\
\text { Padrão }\end{array}$ \\
\hline $\begin{array}{l}\text { Este anúncio é } \\
\text { muito atraente } \\
\text { para mim. }\end{array}$ & 2,93 & 1,136 & 3,85 & 0,870 \\
\hline 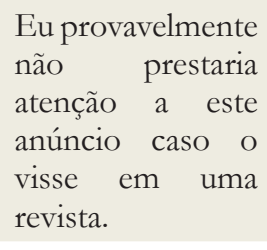 & 2,80 & 1,144 & 2,45 & 1,070 \\
\hline $\begin{array}{l}\text { Este é um anúncio } \\
\text { caloroso e mexe } \\
\text { com o emocional. }\end{array}$ & 2,91 & 1,120 & 3,49 & 0,934 \\
\hline $\begin{array}{lr}\text { Este } & \text { anúncio } \\
\text { me fez } & \text { desejar } \\
\text { comprar } & \text { o } \\
\text { produto } & \text { ou } \\
\text { serviço. } & \end{array}$ & 3,88 & 0,781 & 4,08 & 0,607 \\
\hline $\begin{array}{l}\text { Este anúncio } \\
\text { é pouco } \\
\text { interessante para } \\
\text { mim. }\end{array}$ & 3,03 & 1,139 & 2,21 & 0,938 \\
\hline $\begin{array}{l}\text { Eu não gosto } \\
\text { deste anúncio. }\end{array}$ & 2,69 & 1,058 & 2,02 & 0,933 \\
\hline $\begin{array}{l}\text { Este anúncio me } \\
\text { faz sentir bem. }\end{array}$ & 2,75 & 0,957 & 3,67 & 0,775 \\
\hline $\begin{array}{l}\text { Este é um anúncio } \\
\text { maravilhoso. }\end{array}$ & 2,62 & 1,002 & 3,67 & 0,859 \\
\hline $\begin{array}{l}\text { Este é um anúncio } \\
\text { que se esquece } \\
\text { com facilidade. }\end{array}$ & 3,06 & 1,082 & 2,59 & 1,018 \\
\hline
\end{tabular}

\begin{tabular}{lllll}
$\begin{array}{l}\text { Este é um anúncio } \\
\text { fascinante. }\end{array}$ & 2,66 & 0,971 & 3,52 & 0,841 \\
$\begin{array}{l}\text { Estou cansado(a) } \\
\text { deste tipo de }\end{array}$ & 2,96 & 1,003 & 2,12 & 0,928 \\
$\begin{array}{l}\text { anúncio. } \\
\begin{array}{l}\text { Este anúncio me } \\
\text { causa arrepio. }\end{array}\end{array}$ & 2,23 & 0,924 & 2,48 & 0,974 \\
\hline $\begin{array}{l}\text { Confiabilidade } \\
\text { da escala (Alpha } \\
\text { de Cronbach) }\end{array}$ & $\mathbf{0 , 8 3 0}$ & & $\mathbf{0 , 8 4 0}$ & \\
\hline
\end{tabular}

Fonte: elaborado pelos autores (2015)

Nota: as variáveis destacadas em cinza estão escritas de maneira desfavorável.

Em uma análise individual dos anúncios, verificou-se que o anúncio da marca icônica não obteve, de modo geral, uma avaliação positiva, uma vez que o anúncio não se mostrou atraente e se mostrou pouco efetivo, especialmente no sentido das pessoas lembrarem seu conteúdo. Não obstante, as demais questões obtiveram análises intermediárias, cabendo ressaltar que houve amplitude e desvio padrão altos, o que dá a ideia de que a Coca-Cola costuma levantar sentimentos extremos em seus consumidores, ou seja, poder-se-ia dizer que os consumidores ou amam ou odeiam a marca. Do mesmo modo, existe um discurso 'politicamente correto' a respeito do consumo dos produtos da marca (que vêm sendo considerados pouco saudáveis e condenados por diversos grupos de pressão), o que pode afetar a avaliação dos consumidores em relação à marca.

Isso pode ser explicado pela dimensão simbólica que uma marca aufere de seus consumidores. A dimensão simbólica considera a marca em um nível emocional, onde os produtos são avaliados por sua capacidade de comunicar algo, de significar, de ser (e não por sua utilidade) (SIRGY; SU, 2000). Evidencia-se ainda, que os consumidores não baseiam suas escolhas apenas no aspecto racional. Isto é, eles precisam se sentir inseridos nos círculos sociais e pertencer a grupos de referência. Logo, precisam de marcas que adicionem significado à sua própria existência, que se identifiquem com seu estilo de vida e ajudem a expressar sua personalidade (MELLO et al., 2006). Logo, se os grupos de referência estão adotando novos estilos de vida, podem influenciar a avaliação dos anúncios que levam o nome da marca, como uma consequência de sua necessidade de pertencer.

Contudo, se observado o propósito da publicidade de promover a ação de compra - além das outras 
funções, como dar maior identidade ao produto e à empresa, explicitar os benefícios e as vantagens do produto (SHIMP, 2002) - verifica-se que o anúncio da Coca-Cola pode ser considerado efetivo, pois apesar do anúncio não receber uma avaliação positiva, quando se refere a despertar o desejo de consumo e compra do produto, o anúncio mostrou-se eficaz (média 3,88 e desvio padrão 0,781).

Em contraponto, a reação emocional foi mais positiva ao anúncio da marca local. Verificou-se que o anúncio mostrou-se atraente, caloroso, fascinante e foi considerado maravilhoso por grande parte da amostra. Esta avaliação pode ser explicada, observando que a própria imagem que endossa o anúncio, tendo como fundo uma criança, de modo geral, mexe com os sentimentos, emoções e atitudes das pessoas, podendo influenciar a decisão da pessoa a ser persuadida - uma das formas de influência social propostas por Pratkanis (2007). Do mesmo modo, em relação à marca local, há uma relação mais próxima da comunidade com a empresa e que isto pode, também, afetar a percepção em relação à publicidade.

Verificou-se ainda que o anúncio despertou a intenção de compra do serviço, mostrando um elevado índice de aceitação. Isso mostra, que assim como o anúncio da marca icônica, a publicidade atendeu a um de seus propósitos centrais. Ratifica-se, deste modo, os resultados de Cha (2009), Hoy e Milne (2009) e Kelly et al. (2010), que mostraram a publicidade online como eficaz nas respostas dos usuários para compras. Finalmente, infere-se que a relação dos respondentes com a marca, no mundo real pode impactar a avaliação da publicidade em mídias sociais (DREZE; HUSSHERR, 2003).

\section{Cálculo do quociente emocional de Wells}

Após a análise descritiva dos anúncios, verificou-se o valor do quociente emocional dos anúncios analisadas. Para tal, utilizou-se o cálculo original proposto em Wells (1964). A escala é composta por 12 variáveis observáveis. Destas, seis são favoráveis, e para o cálculo, soma-se estas ao número de discordâncias (desfavoráveis), também composto por seis variáveis observáveis. Após, dividiu-se este escore por 12 (número total de variáveis). Optouse por não remover o decimal (fazendo a multiplicação por 100). De modo a obter uma pontuação única para cada anúncio publicitário, procedeu-se com uma média das pontuações recebidas de todos os entrevistados, para cada levantamento.

Os resultados desse procedimento estão apresentados na Tabela 3, que demonstra a média e o desvio padrão do quociente emocional obtido para cada um dos anúncios. Tendo por base o quociente emocional, ratifica-se que o anúncio da marca local obteve o quociente emocional mais elevado, se comparado com o anúncio da marca icônica.

Tabela 3: Cálculo do quociente emocional (QE) e análises por gênero e escolaridade

\begin{tabular}{llllllll}
\hline & & $\begin{array}{l}\text { QE } \\
\text { Geral }\end{array}$ & $\begin{array}{l}\text { Gênero } \\
\text { M }\end{array}$ & F & $\begin{array}{l}\text { Escolaridade } \\
\text { Ensino Médio }\end{array}$ & Ensino Superior & Pós-Graduação \\
\hline $\begin{array}{l}\text { Marca Icônica } \\
(985 \text { casos })\end{array}$ & Média & 2,87 & 2,89 & 2,86 & 2,92 & 2,87 & 2,87 \\
\hline $\begin{array}{l}\text { Desvio } \\
\text { Padrão }\end{array}$ & 0,367 & 0,399 & 0,340 & 0,496 & 0,354 & 0,366 \\
\hline $\begin{array}{l}\text { Marca Local } \\
\text { Média }\end{array}$ & 3,01 & 3,03 & 3,00 & 3,00 & 3,00 & 3,06 \\
\hline
\end{tabular}

Fonte: elaborado pelos autores (2015)

Nota: $\mathrm{M}=$ Masculino; $\mathrm{F}=$ Feminino

*** $\mathrm{O}$ teste $\mathrm{t}$ de student não identificou diferenças significativas entre os grupos.

A Tabela 3 apresenta ainda, o quociente emocional para cada um dos anúncios, considerando os diferentes grupos, delimitados pelo gênero e pela escolaridade. Tal análise, pautou-se nos pressupostos de que as características do consumidor, tais como gênero e cultura, são capazes de influenciar a eficácia de um anúncio online (JU, 2013; MELLO et al., 2006; PALANISAMY, 2005; ZENG et al., 2009). 
Verificou-se ainda que, em ambos os casos, houve uma diferença aparente de média entre os grupos, considerando que os homens reagiram mais positivamente a ambos os anúncios. No que tange à escolaridade, verificou-se que a publicidade da marca icônica foi melhor avaliada pelo grupo que possui menor índice de escolaridade, em detrimento dos demais grupos. Para a marca local, verificou-se que o grupo formado pelos pós-graduados, ou seja, grupo com maior grau de escolaridade, avaliou mais positivamente a marca.

Infere-se contudo, que a diferença entre as médias (procedida por meio do teste $t$ de student) não foi significativa para nenhuma característica socioeconômica analisada. Outrossim, ressalta-se que não foi o objetivo mensurar a diferença entre os dois anúncios em si, considerando que estes possuem objetivos distintos e foram avaliados por grupos distintos, o que pode ser um fator a ser explorado em estudos posteriores.

\section{Considerações Finais}

Este estudo partiu da verificação da lacuna teórica de que as investigações sobre a publicidade em mídias sociais não costumam descrever as emoções dos consumidores sobre os anúncios. Deste modo, este estudo se propôs a descrever as respostas dos consumidores para anúncios reais expostos em duas comunidades de marca no Facebook: uma de marca icônica e a outra de uma marca local.

Tendo por base as análises, verificou-se que embora a ênfase do anúncio da marca icônica fosse de gerar engajamento e envolvimento de seus seguidores (o que aconteceu se observados apenas o número de comentários, curtidas e compartilhamentos da imagem no Facebook), a resposta emocional do anúncio não obteve uma avaliação positiva. Contudo, mesmo que o anúncio não tenha despertado emoções mais intrínsecas no que tange à imagem e mesmo não sendo o foco principal do anúncio, mostrou-se efetivo no sentido de despertar o desejo de compra/consumo do produto por parte dos respondentes.

O anúncio da marca local, por sua vez, obteve um engajamento muito menor se observados o número de comentários, compartilhamentos e curtidas na página da marca no Facebook. Contudo, no que se refere à avaliação intrínseca da imagem, o anúncio mostrou- se atraente, caloroso, fascinante e foi considerado maravilhoso por grande parte da amostra - o que elevou os escores da reação emocional dos respondentes. Tendo por base o objetivo do anúncio, que se mostrava mais voltado a incentivar o consumo dos serviços da empresa, o anúncio revelou-se muito eficaz.

Assim, por meio do presente estudo, mesmo em seu caráter descritivo, é possível fazer algumas contribuições teóricas. Em primeiro lugar, o tipo de anúncio (que busca engajamento ou que busca promover o consumo do produto) parece não influenciar diretamente no desejo de compra/ consumo do produto, considerando que ambos os anúncios elevaram a disposição dos consumidores para a compra dos produtos/serviços. Em segundo lugar, dada a amplitude das respostas do anúncio da Coca-Cola, a crença dos seguidores a respeito da marca parece influenciar a análise dos anúncios, ou seja, o sentimento que a pessoa possui a respeito do produto não pode ser separado da avaliação ou análise da marca. Em terceiro lugar, as características sociodemográficas (escolaridade e gênero), ao contrário do sugerido na literatura anterior, não se mostraram significantes na análise dos anúncios.

Considerando o exposto, é necessário que as marcas reflitam as diferentes dimensões que os anúncios podem tomar ao longo tempo, que é imprescindível a decisão sobre qual é o objetivo da publicidade. Ademais, a marca é mais do que a simples soma do produto e de seu significado transmitido aos consumidores por meio da publicidade, gerando também neles um mutualismo e dependência com a marca e com a comunicação veiculada pelas diferentes mídias.

Como limitantes, este estudo apresenta o tipo de pesquisa, que se concentrou na descrição da reação emocional dos consumidores a dois anúncios. Logo, o contexto pode ser considerado uma fronteira e pode comprometer a generalização dos resultados. Ainda como limitação ao estudo, indica-se a escolha dos anúncios inseridos no instrumento de coleta de dados, que foi aleatória. Entende-se que diferentes anúncios poderiam gerar diferentes resultados.

Este é um estudo preliminar sobre avaliação emocional de anúncios em mídias sociais. Pesquisadores podem conduzir novas pesquisas para aprofundar o conhecimento sobre os efeitos de diferentes tipos de campanhas de marketing em mídias sociais, sobre o efeito de características sociodemográficas sobre a 
análise, entre outros - com o objetivo de traçar as melhores práticas de marketing neste tipo de mídia. Pode-se ainda, desenvolver estudos que envolvam as diferentes perspectivas dos anúncios, onde de um lado verifique-se a intenção da empresa e de outro verifique-se a reação dos consumidores. Finalmente, tanto profissionais quanto os acadêmicos podem aplicar estudos que revelem os possíveis efeitos da inteligência artificial, da computação em nuvem e de identidades online sobre a comunicação das marcas.

\section{Referências}

BALTAS, G. Determinants of internet advertising effectiveness: an empirical study. International Journal of Market Research, v. 45, n.4, p.505-513, 2003.

BARAGGIOLI, F.; BRASEL, S.A. Visual velocity: content font effects and incidental online ad exposure. Advances in Consumer Research, v.35, p. 600606, 2008.

BOYD, D.M.; ELLISON, N.B. Social network sites: Definition, history, and scholarship. Journal of Computer-Mediated Communication, v.13, n.1, p.210-230, 2007.

CASALÓ, L.V.; FLAVIÁN, C.; GUINALIU, M. Promoting Consumer's Participation in Virtual Brand Communities: A New Paradigm in Brand Strategies. Journal of Marketing Communication, v.14, n.1, p. 19-36, 2008.

CHA, J. Shopping on Social Networking Web Sites: Attitudes toward Real versus Virtual Items. Journal of Interactive Advertising, v.10, n.1, p.77-93, 2009.

CHANG, C. Self-congruency as a cue in different advertising-processing contexts. Communication Research, v.29, n. 5, p.503-536, 2002.

CHI, H. Interactive Digital Advertising VS. Virtual Brand Community: Exploratory Study of User Motivation and Social Media Marketing Responses in Taiwan.Journal of Interactive Advertising, v.12, p.44-61, 2011.

COON, M. Social Media Marketing: Successful Case Studies of Businesses Using Facebook and YouTube With An InDepth Look in the Business Use of Twitter. Communication M.A. Project, June 4, 2010. Disponível em: http://comm.stanford.edu/coterm/ projects/2010/maddy\%20coon.pdf. Acesso em abril 2013.

COHEN, J.B.; ARENI, C. Affect and consumer behaviour. In: ROBERTSON, S.T.; KASSARJIAN, H.H. (eds). Handbook of consumer behaviour. New Jersey: Prentice Hall; 1991.

DERBAIX, C.; PHAM, M.T. Affective reactions to consumption situations: a pilot investigation. Journal of Economic Psychology, v.12, p.2, p.325-55, 1991.

DRĖZE, X.; HUSSHERR, F.X. Internet advertising: is anybody watching? Journal of Interactive Marketing, v.17, n.8-23, 2003.

EDELL, J.A.; BURKE, M.C. The power of feelings in understanding advertising effects. The Journal of Consumer Research, v.14, n.3, p.421-433, 1987.

ERDOGMUS, I.E.; ÇIÇEK,M. The Impact of Social Media Marketing on Brand Loyalty. Procedia Social and Behavioral Sciences, v.58, p.1353-1360, 2012.

FARRIS, P.W.; BENDLE, N.T.; PFEIFER, P.E.; REIBSTEIN, D.J. Marketing Metrics: 50+ Metrics Every Executive Should Master. Upper Saddle River: Prentice Hall, 2006.

GHOSH, H.; BHATNAGAR, A. On Measuring and Increasing the Effectiveness of Banner Advertising. MIS Review, v.19, n.1, p. 25-44, 2013.

GOEL, S.; HOFMAN, J. M.; SIRER, M. I. Who does what on the web: Studying web browsing behavior at scale. In:Proc. 6th International Conference on Weblogs and Social Media, 2012.

GOLAN, G.J.; ZAIDNER, L. Creative Strategies in Viral Advertising: An Application of Taylor's Six Segment Message Strategy Wheel. Journal of ComputerMediated Communication, v. 13, p.959-72, 2008.

GOODMAN, L.A. Snowball sampling. The annals of Mathematical Statistics, v.32, p.148-170, 1961.

HOY, M.G.; MILNE, G. Gender Differences in Privacy-Related Measures for Young Adult Facebook Users. Journal of Interactive Advertising, v.10, n.2, p.2845, 2010.

HOLBROOK, M.B.; CHESNUT, R.W.; OLIVA, T.A.; GREENLEAF, E.A. Play as a consumption experience: the roles of emotions, performance and personality in the enjoyment of games. The Journal of Consumer Research, v.11, n.2, p.328-391, 1984.

Interbrand. Best Global Brands 2012. Disponível em: http://www.interbrand.com/pt/best-globalbrands/2012/Best-Global-Brands-2012.aspx. Acesso em 30-12-2012.

JU, B. A proposed cross-cultural examination of online advertising effectiveness in china and the UK. 
International Journal of Business and Management, v.8, n.6, p.34-39, 2013.

KELLER, K.L. Building Strong Brands in a Modern Marketing Communications Environment. Journal of Marketing Communications, v.15, n.2-3, p.139-55, 2009.

KELLY, L.; KERR, G.; DRENNAN, J. Avoidance of Advertising in Social Networking Sites: The Teenage Perspective. Journal of Interactive Advertising, v.10, n.2, p.16-27, 2010.

LADHARI, R. The movie experience: a revised approach to determinants of satisfaction. Journal of Business Research, v.60, n.5, p.454-462, 2007.

LEE, J.W.; AHN, J.H. Attention to banner ads and their effectiveness: an eye-tracking approach. International Journal of Electronic Commerce, v.17, n.1, p. 119-138, 2012.

LIBAI, B.; BOLTON, R.; BÜGEL, M.S.; RUYTER, K.; GÖTZ, O.; HANS, R.; STEPHEN, A.T.

Customer-to-Customer Interactions: Broadening the Scope of Word of Mouth Research. Journal of Service Research, v.13, n.3, p.267-82, 2010.

LIN, H. Understanding Behavioral Intention to Participate in Virtual Communities. Cyberpsychology \& Behavior, v.9, n.5, p.540-547, 2006.

MALHOTRA, N.K. Pesquisa de marketing: uma orientação aplicada. $3^{\mathrm{a}} \mathrm{ed}$. Porto Alegre/RS: Bookman, 2001.

MANGOLD, W. G.; FAULDS, D. Social Media: The new hybrid element of the promotion mix. Business Horizons, v.52, n.4, p. 357-365, 2009.

MELLO, S.C.B.; FONSÊCA, F.R.B.; SOUZA NETO, A.F.; LEÃO, A.L.M.S. Acessando a reação emocional à propaganda por meio da Escala Wells. Revista de Administração FACES Journal, v. 5, n. 1, p. 26-40, 2006.

OLIVER, R.L. Conceptual issues in the structural analysis of consumption emotion, satisfaction and quality: evidence in a service setting. In: ALLEN, C.T.; JOHN, D.R. (edds.). Advances in Consumer Research. Provo-UT: Association of Consumer Research: 1994.

PALANISAMY, R. Impact of gender differences on online consumer characteristics on web-based banner advertising effectiveness. Journal of Services Research, v.4, n.2, p. 45-55, 2004.

PINHO, J.C.; SOARES, A.M. The role of social capital on online social newtorks. International Journal of Consumer Studies, v.39, p.239-248, 2015.

PRATKANIS, A. R. The science of social influence: advances and future progress. Nova York: Psychology Press, 2007.

Reuters Brasil. América Latina impulsiona resultados do Facebook (01-08-2013). Disponível em: http://br.reuters.com/article/ internetNews/idBRSPE97009R20130801? pageNumber $=2 \&$ virtualBrandChannel $=0$. Acesso em 20-09-2014.

ROBINSON, H.;WYSOCKA, A.;HAND, C. Internet advertising effectiveness: The effect of design on click-through rates for banner ads.

International Journal of Advertising, v.26, p.4, p.527-541, 2007.

ROSENKRANS, G. Maximizing user interactivity through banner ad design. Journal of Promotion Management, v.16, n. 3, p. 265-287, 2010.

RUSSELL, M.G. A Call for Creativity in New Metrics for Liquid Media. Journal of Interactive Advertising, v.9, n.2, p.3-24, 2009.

SHIMP, T. A. Propaganda e Promoção. 5. ed.Porto Alegre: Bookman, 2002.

SCHLOSSER, A.; SHAVITT, S.; KANFER A. Survey of internet users'attitudes toward Internet advertising. Journal of Interactive Marketing, v.13, p.3454, 1999.

SIRGY, M. J.; SU, C. Destination image, selfcongruity,and travel behavior: Toward anintegrative model. Journal of Travel Research, v.38, n.4, p.340-52, 2000 .

SHAO, A.T. Nonconformity advertising to teens. Journal of Advertising Research, v.42, n.3, p.56-65, 2002.

SCHOEFER, K.; DIAMANTOPOULOS, A. A typology of consumers' emotional response styles during service recovery encounters. British Journal of Man, v.20, n.3, p.292-308, 2009.

SocialBakers. List of Countries on Facebook. Disponível em: http://www.socialbakers.com/facebookstatistics/. Acesso em 27-11-2014.

SUN, Y.; LIM, K.H.; JIANG, C.; PENG, J. Z.; Chen, $\mathrm{X}$. Do males and females think in the same way? An empirical investigation on the gender differences in Web advertising evaluation. Computers in Human Behavior, v.26, n.6, p.1614-1624, 2010.

THORSON, E.; CHI, A.; LEAVIT'T, C. Attention, Memory, Attitude, and Conation: a Test of the 
Advertising Hierarchy. In: SHERRY, J.F.; BRIAN S. Advances in Consumer Research, Provo, UT: Association for Consumer Research, 1992.

TUBENCHLAK, D. B.; FAVERI, D.; ZANINI, M. T.; GOLDSZMIDT, R. Motivações da comunicação boca a boca eletrônica positiva entre consumidores no Facebook . Revista de Administração Contemporânea, v. 19, n. 1, p. 107-126, 2015.

TUCKER, C. Social advertising. (2012) SSRN eLibrary. Disponível em: http://ssrn.com/paper=1975897. Acesso em abril/2014.

UTZ, S. The (Potential) Benefits of Campaigning via Social Network Sites. Journal of Computer-Mediated Communication, v.14, n.2, p.221-43, 2009.

YAVEROGLU, I.; DONTHU, N. Advertising repetition and placement issues in on-line environments. Journal of Advertising, v.37, n.2, p.31-43, 2008.

WANG, K.Y.; SHIH, E.; PERACCHIO, L.A.

How banner ads can be effective: investigating the influences of exposure duration and banner ad complexity. International Journal of Advertising, v. 32, n.1, p. 121-141, 2013.

WELLS, W. D. EQ, son of EQ, and the reaction profile. Journal of Marketing, n.28, p.45-52, oct., 1964.

ZEELENBERG, M.; PIETERS, R. Beyond valence in customer dissatisfaction: a review and new findings on behavioral responses to regret and disappointment in failed services. Journal of Business Research, v.57, n.4, p.445-455, 2004.

ZENG,F.; HUANG, L.; DOU,W. Social factors in user perceptions and responses to advertising in online social networking communities. Journal of Interactive Advertising, v.10, n.1, p. 1-13, 2009.

ZIKHAN, G.M.; BURTON, S. An examination of three multidimensional profiles for assessing consumer reactions to advertisements. Journal of Advertising, v. 18, p. 6-14, 1989. 